\title{
Communication
}

\section{Fiber Optic Load Cells with Enhanced Sensitivity by Optical Vernier Effect}

\author{
Tiago Paixão ${ }^{1, *(\mathbb{D}}$, Ricardo Ferreira ${ }^{1}$, M. Fátima Domingues ${ }^{2}\left(\mathbb{C}\right.$ and Paulo Antunes ${ }^{1,2} \mathbb{0}$ \\ 1 I3N and Physics Department, Campus of Santiago, University of Aveiro, 3810-193 Aveiro, Portugal; \\ ricardo.a.moreira@ua.pt (R.F.); pantunes@ua.pt (P.A.) \\ 2 IT-Instituto de Telecomunicações, University of Aveiro, 3810-193 Aveiro, Portugal; fatima.domingues@ua.pt \\ * Correspondence: tiagopaixao@ua.pt
}

Citation: Paixão, T.; Ferreira, R.; Domingues, M.F.; Antunes, P. Fiber Optic Load Cells with Enhanced Sensitivity by Optical Vernier Effect. Sensors 2021, 21, 7737. https:/ / doi.org/10.3390/s21227737

Academic Editor: Yuliya Semenova

Received: 21 October 2021

Accepted: 15 November 2021

Published: 20 November 2021

Publisher's Note: MDPI stays neutral with regard to jurisdictional claims in published maps and institutional affiliations.

Copyright: (c) 2021 by the authors. Licensee MDPI, Basel, Switzerland. This article is an open access article distributed under the terms and conditions of the Creative Commons Attribution (CC BY) license (https:// creativecommons.org/licenses/by/ $4.0 /)$.

\begin{abstract}
Developing technologies capable of constantly assessing and optimizing day-to-day activities has been a research priority for several years. A key factor in such technologies is the use of highly sensitive sensors to monitor in real-time numerous parameters, such as temperature and load. Due to their unique features, optical fiber sensors became one of the most interesting and viable solutions for applications dependent on those parameters. In this work, we present an optical fiber load sensor, called load cell, based on Fabry-Pérot hollow cavities embedded in a polymeric material. By using the load cells in a parallel configuration with a non-embedded hollow cavity, the optical Vernier effect was generated, allowing maximum sensitivity values of $0.433 \mathrm{~nm} \mathrm{~N}^{-1}$ and $0.66 \mathrm{~nm}{ }^{\circ} \mathrm{C}^{-1}$ to be attained for vertical load and temperature, respectively. The proposed sensor's performance, allied with the proposed configuration, makes it a viable and suitable device for a wide range of applications, namely those requiring high thermal and load sensitivities.
\end{abstract}

Keywords: optical fiber sensors; load sensing; optical Vernier effect; Fabry-Pérot interferometer

\section{Introduction}

Optical fiber sensors (OFSs) have been used extensively in recent years in several fields (from biology to civil engineering), mainly due to their intrinsic advantages, such as their light weight, immunity to electromagnetic fields, multiplexing capabilities, electrical passiveness at the point-of-care, and multiparameter sensing [1,2]. Despite the numerous features of conventional OFSs, the limits of sensing resolutions are being reached. Therefore, efforts are being made to improve OFS resolutions, either by using new materials or adopting novel sensing configurations. Recently, one of the most attractive and commonly used techniques to increase the sensitivity of optical fiber sensors is the optical Vernier effect (OVE). Despite being solely used within interferometry-based OFSs, the inherent advantages of this effect, such as the possibility to tune OFSs' sensitivities and develop highly compact devices, have allowed researchers to reach unprecedented sensitivity values, mainly in applications for temperature $[3,4]$, strain $[5,6]$, magnetic fields $[6,7]$ and refractive index monitoring [8,9].

In this work, an optical fiber sensor, based on a hollow Fabry-Pérot interferometer (FPI), embedded in resin, for temperature and vertical load monitoring, is reported. The sensors' sensitivity was magnified using the optical Vernier effect, resulting from coupling, in a parallel configuration, the embedded sensor with an additional FPI cavity insensitive to temperature variations, eliminating the need to adopt complex isolation schemes or mathematical compensation methods. The thermal and load characterization revealed a linear response throughout the entire tested ranges and a dynamic range up to a maximum value of approximately $150 \mathrm{~N}$. The attained results, allied with the low-cost fabrication methods and devices' compactness, unveil the enormous potential of this sensor's configuration to be used in a wide range of different applications, acting either as a load cell or temperature sensor. 


\section{Materials and Methods}

The developed sensor comprises two different FPIs, namely reference and sensing FPI (rFPI and sFPI, respectively). Both FPIs were fabricated based on the methodology previously reported by our team [10], which consists of the recycling of optical fibers previously damaged by the fiber fuse effect. This catastrophic phenomenon completely destroys the optical fiber along its path, leaving periodic voids along the optical fiber core, as visible in Figure 1, on the left. These periodic voids inhibit the optical fiber's transmission abilities, rendering it useless for communications purposes. Nevertheless, its use for the production of inline Fabry-Pérot optical fiber interferometric sensors has been exhaustively explored [10-12]. The methodology to produce the FPI sensors is based on the machine splicing technique and is also depicted in Figure 1: It starts with the normal splice between the damaged fiber and the normal SMF fiber, which results in a void with higher dimensions in the splice region. The following step is to cleave this fiber in the splice region in order to isolate the void with higher dimensions. Afterwards, this fiber is spliced again to another SMF fiber, which results in a hollow microcavity, as depicted in Figure 1, on the right. The size of the resulting microcavity can be controlled by the size of the void in the 2nd splice (which is set by the cleave point).

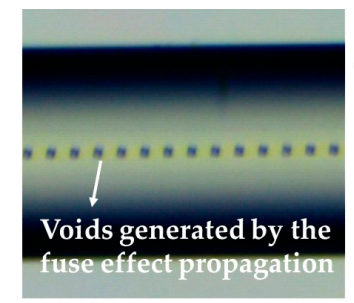

Optical fiber damaged by fuse effect.

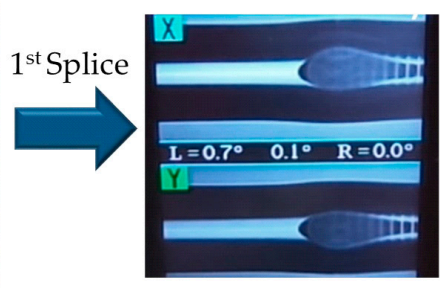

Resulting void, from the splice between a normal SMF fiber and a damaged fiber.

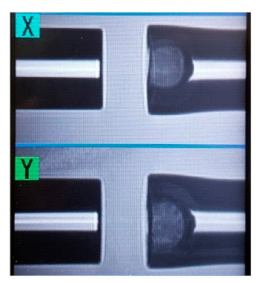

Fiber cleavage; $2^{\text {nd }}$ splicing to a standard fiber

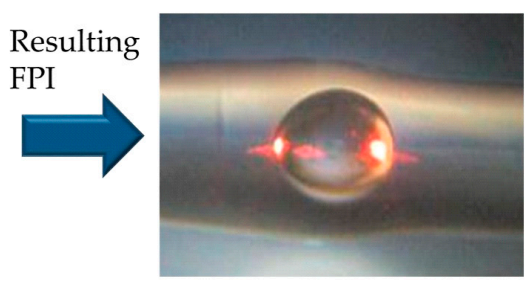

Final hollow microcavity, with a visible red optical signal ressonance.

Figure 1. Hollow microcavity production by the recycling of optical fiber damaged by the catastrophic fiber fuse effect.

Assembling the load cells comprised of the encapsulation of the FPIs (one for each pair of rFPI and sFPI). Two 3D printed molds with a different height $(h)$ and width $(w)$ were used (the length $(l)$ was kept constant) to evaluate the influence of the resin volume on the sensitivity of the load cells. The optical fiber containing the hollow microcavity was placed at the center of the cell's cast, which was then filled with a thermal setting epoxy resin (Liquid Lens), as depicted in Figure 2. The resin was left to cure for $24 \mathrm{~h}$ to guarantee its full solidification, after which the resin block with the embedded optical fiber (load cell) was extracted from the mold. The used molds, as well as the resulting structures, are depicted in Figure 2.

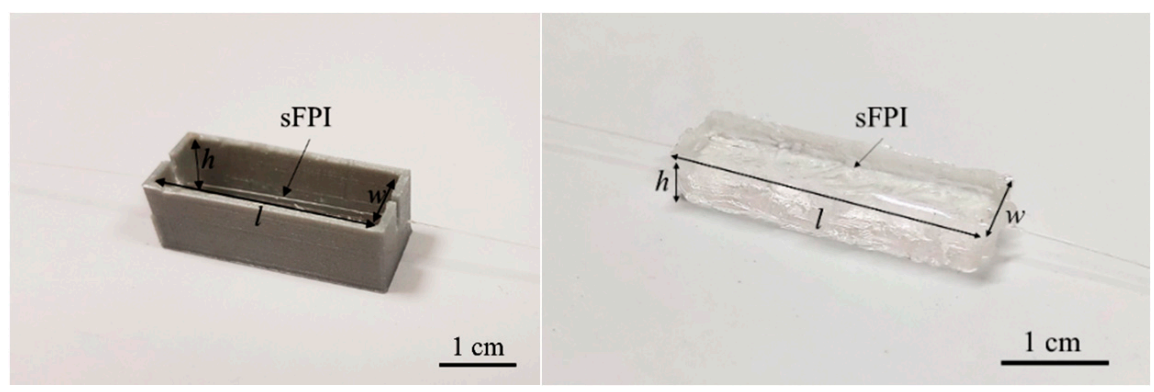

Figure 2. Load cell production apparatus and the resulting load cells. sFPI stands for the sensing FPI, which comprises the two different load cells $\left(\mathrm{LC}_{1}\right.$ or $\left.\mathrm{LC}_{2}\right)$, and $l, h$ and $w$ are the cell's length, height and width, respectively. 
To generate the OVE, one needs to overlap two interferometric signals, either in series or parallel configuration, with slightly detuned frequencies. Such superposition gives origin to a beating shape spectrum, which can usually be modulated by an envelope function $[13,14]$. Typically, one can fully describe the OVE envelope in terms of its free spectral range (FSR env). Assuming the specific case of OVE generation by two FPIs in a parallel configuration, where one acts as reference (rFPI) and the other one as sensing element (sFPI), the FSR env is given as [4,6]:

$$
\mathrm{FSR}_{\text {env }}=\left|\frac{\mathrm{FSR}_{\mathrm{r}} \mathrm{FSR}_{\mathrm{s}}}{\mathrm{FSR}_{\mathrm{r}}-\mathrm{FSR}_{\mathrm{s}}}\right|,
$$

where $\mathrm{FSR}_{\mathrm{r}}$ and FSR $\mathrm{s}$ are the free spectral ranges of rFPI and sFPI, respectively. The FSR of each FPI can be written as [13,15]:

$$
\mathrm{FSR}_{\mathrm{r}, \mathrm{s}}=\frac{\lambda_{1} \lambda_{2}}{2 \mathrm{~nL} \mathrm{~L}_{\mathrm{r}, \mathrm{s}}}
$$

$\lambda_{1,2}$ being the central wavelengths of two adjacent maxima/minima, and $\mathrm{n}$ and $\mathrm{L}$ the FPIs' cavity medium refractive index and physical length, respectively. Considering the rough approximation $\lambda_{1} \lambda_{2} \approx \lambda^{2}$, Equation (2) can be further simplified:

$$
\mathrm{FSR}_{\mathrm{r}, \mathrm{s}}=\frac{\lambda^{2}}{2 \mathrm{~nL}_{\mathrm{r}, \mathrm{s}}}
$$

Assuming that $\mathrm{rFPI}$ and sFPI reflection spectra $\left(\mathrm{R}_{\mathrm{r}, \mathrm{s}}\right)$ can be mathematically described as $[4,6]$ :

$$
\mathrm{R}_{\mathrm{r}, \mathrm{s}}=\mathrm{a}_{\mathrm{r}, \mathrm{s}} \cos \left(\frac{4 \pi \mathrm{L}_{\mathrm{r}, \mathrm{s}}}{\lambda}\right),
$$

where $a_{r, s}$ is an arbitrary reflection amplitude, the OVE spectrum shall be given by the sum of the two FPIs' spectra, as schematically represented in Figure 3.
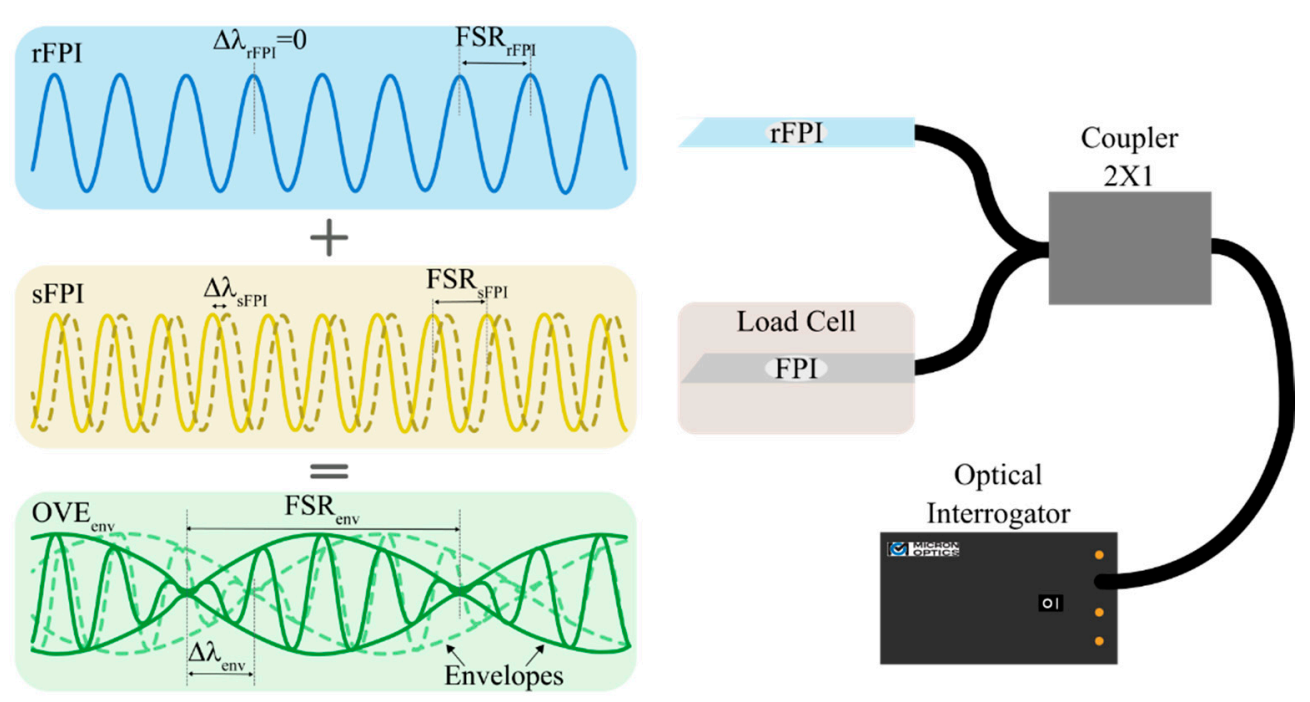

Figure 3. Schematic representation of the OVE-based load cells' spectral monitoring mechanism in a parallel configuration. The solid and dashed lines represent the spectra before and after applying an external stimulus, respectively.

One of the most important figures of merit of the OVE is the magnification factor (M). By definition, $M$ represents the sensitivity enhancement ratio between sFPI and the OVE 
envelope. Considering $\mathrm{S}_{\mathrm{sFP}}$ and $\mathrm{S}_{\mathrm{env}}$ as the sensitivities of sFPI and the OVE envelope, respectively, $\mathrm{M}$ can be written as:

$$
\mathrm{M}=\frac{\mathrm{S}_{\mathrm{env}}}{\mathrm{S}_{\mathrm{sFPI}}}=\frac{\Delta \lambda_{\mathrm{env}}}{\Delta \lambda_{\mathrm{sFPI}}},
$$

where $\Delta \lambda_{\text {SFPI }}$ and $\Delta \lambda_{\text {env }}$ are the wavelength shifts of each spectrum when an external stimulus is applied.

As depicted in Figure 3, if rFPI is insensitive to the desired measurand, or if it is maintained at constant and controlled conditions, a small wavelength variation experienced by the sFPI originates an enormous wavelength shift of the $\mathrm{OVE}_{\text {env }}$. This principle is called the traditional OVE [16] and was applied to the sensors developed in this work, using the two fiber optic hollow cavities embedded in an epoxy resin (denominated as $\mathrm{LC}_{1}$ and $\mathrm{LC}_{2}$ ) as sFPIs, and as rFPI, a similar fiber optic hollow cavity, but without any embedding material.

Two different load cells $\left(\mathrm{LC}_{1}\right.$ and $\left.\mathrm{LC}_{2}\right)$ were used to assess how the volume distribution of the embedding resin affects the overall load cells' sensitivity. The final dimensions of $\mathrm{LC}_{1}$ and $\mathrm{LC}_{2}$ are presented in Table 1 , and the spectra of $\mathrm{LC}_{1}$ and $\mathrm{LC}_{2}$ (measured in reflection by a Micron Optics optical interrogator, model SM125 with $5 \mathrm{pm}$ of resolution and an acquisition rate of $1 \mathrm{~Hz}$ ), as well as the respective OVE spectra generated in a parallel configuration with the rFPI (denominated $\mathrm{OVE}_{1}$ and $\mathrm{OVE}_{2}$, respectively), are depicted in Figure 4.

Table 1. Physical dimensions of the load cells $\mathrm{LC}_{1}$ and $\mathrm{LC}_{2}$, where $\mathrm{w}, \mathrm{h}$ and $\mathrm{l}$ are the width, height and length of each cell, respectively.

\begin{tabular}{cccc}
\hline Sensor & w $(\mathbf{c m})$ & $\mathbf{h}(\mathbf{c m})$ & $\mathbf{l}(\mathbf{c m})$ \\
\hline $\mathrm{LC}_{1}$ & $1.00 \pm 0.05$ & $0.40 \pm 0.05$ & $3.00 \pm 0.05$ \\
$\mathrm{LC}_{2}$ & $1.70 \pm 0.05$ & $0.90 \pm 0.05$ & $3.00 \pm 0.05$ \\
\hline
\end{tabular}

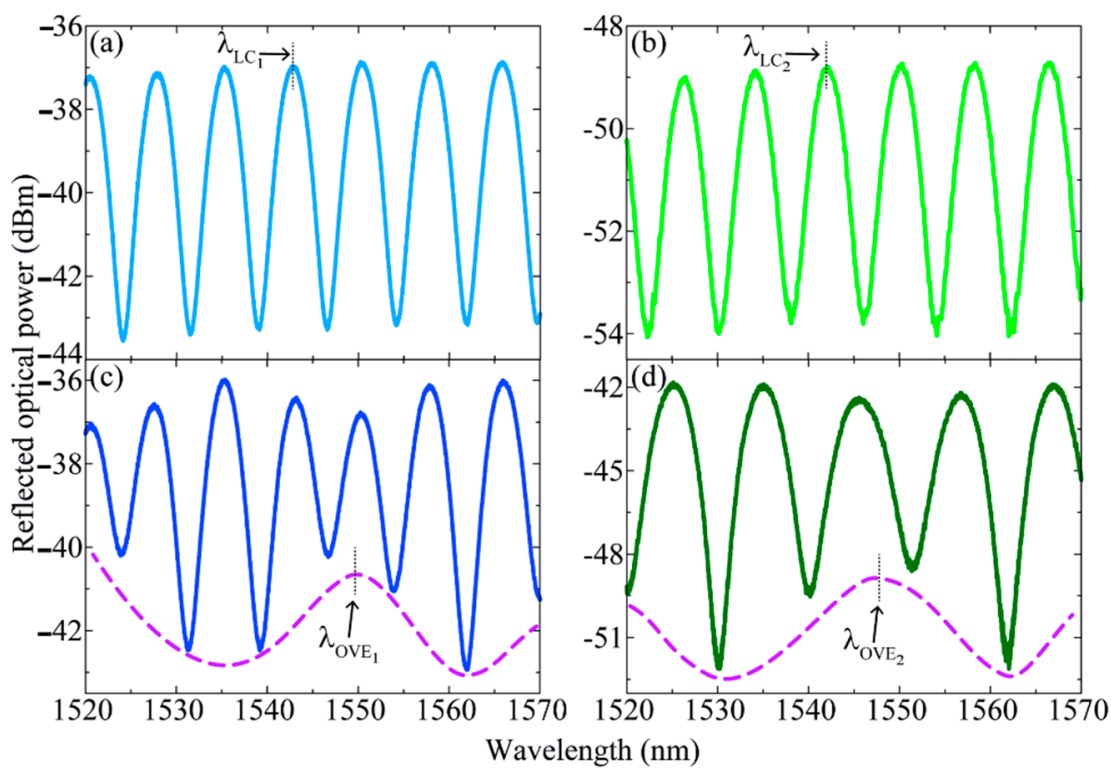

Figure 4. Spectra of (a) $\mathrm{LC}_{1}$, (b) $\mathrm{FPI}_{2}$, (c) $\mathrm{VFPI}_{1}$ and (d) $\mathrm{VFPI}_{2}$. The purple dashed lines in (c,d) represent the lower envelopes of the spectra. $\lambda_{\mathrm{LC} 1,2}$ and $\lambda_{\mathrm{OVE} 1,2}$ are the monitored central wavelengths of the FPIs and OVEs' envelopes, respectively, used in the sensors' characterizations.

When a vertical load is applied to each cell, the embedding resin will contract along the $\mathrm{Z}$ axis and expand in the remaining directions ( $X$ and $Y$ axis). Therefore, a spectra wavelength shift is expected for $\mathrm{LC}_{1}$ and $\mathrm{LC}_{2}$ and, consequently, in $\mathrm{OVE}_{1}$ and $\mathrm{OVE}_{2}$ as 
well. Figure 5 depicts a schematic of the forces involved when a mass is placed on the top of one of the developed load cells, where $\mathrm{L}_{\mathrm{FPI}}$ represents the embedded FPI cavity length, and $\Delta \lambda_{\mathrm{FPI}}$ the correspondent wavelength shift.

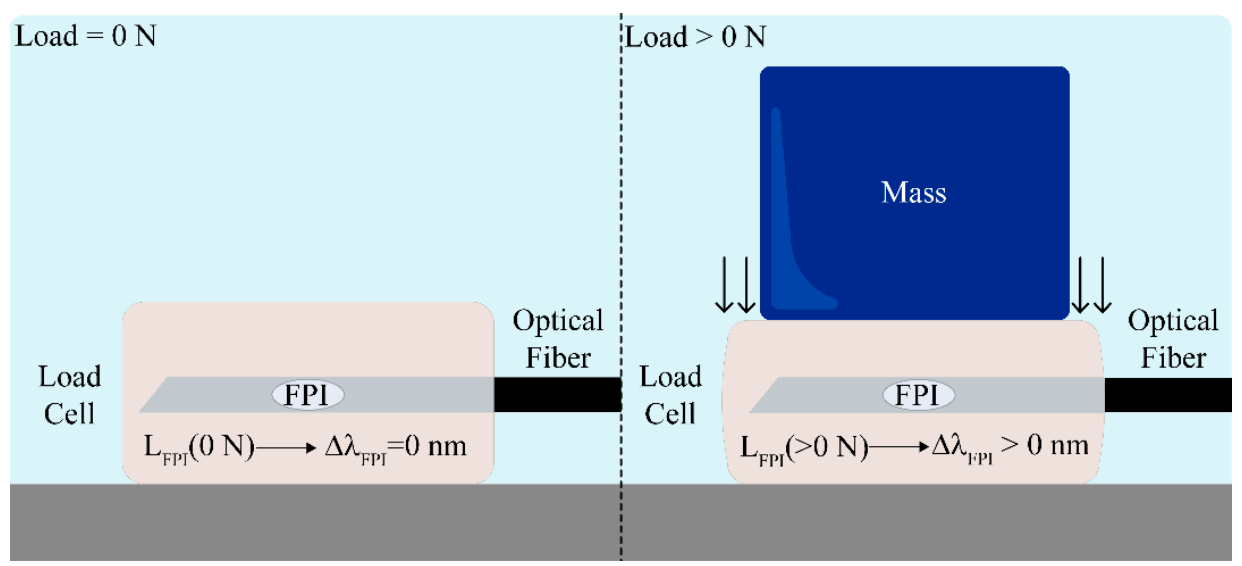

Figure 5. Schematic representation of the load cells under different load forces. For different applied mass, the FPI cavity longitudinal length $\left(\mathrm{L}_{\mathrm{FPI}}\right)$ suffers a variation, which translates into a spectral wavelength shift $\left(\Delta \lambda_{\mathrm{FPI}}\right)$.

\section{Results}

To characterize the developed sensors in terms of temperature and vertical load, two separated setups were assembled.

First, the two sensors were thermally characterized using a climatic chamber (Weiss Technik L C $/ 64 / 70 / 3,0.3{ }^{\circ} \mathrm{C}$ of resolution). The temperature was varied in steps of $5{ }^{\circ} \mathrm{C}$ within the range of $15-50{ }^{\circ} \mathrm{C}$, with a stabilization time of $15 \mathrm{~min}$ at each step. As already reported in the literature, fiber optic FPIs with an air cavity similar to the one of the rFPIs can be considered insensitive to temperature for small thermal variations $[17,18]$. Therefore, the sensing configuration depicted in Figure 6. was adopted, where both LCs were placed inside the climatic chamber along with the rFPI, which was fixed in a glass microscope slide with Kapton tape and left free of applied strain. At each temperature step, the individual spectra of $\mathrm{LC}_{1}$ and $\mathrm{LC}_{2}$ were recorded, as well as $\mathrm{OVE}_{1}$ and $\mathrm{OVE}_{2}$ spectra. A red shift was verified for all sensing elements, as can be seen in Figure 7.

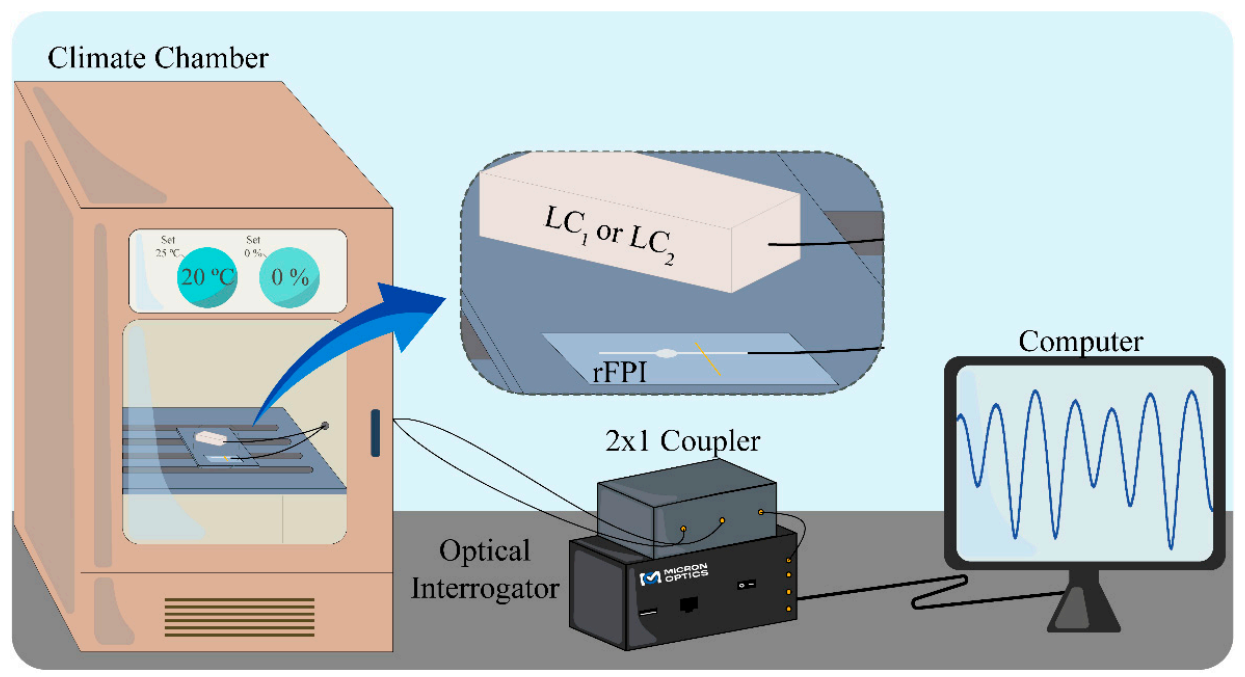

Figure 6. Schematic representation of the setup used in the thermal characterization. The zoom-in depicts the positioning of $\mathrm{LC}_{1}$ (or $\mathrm{LC}_{2}$ ) and $\mathrm{rFPI}$ inside the climate chamber. 

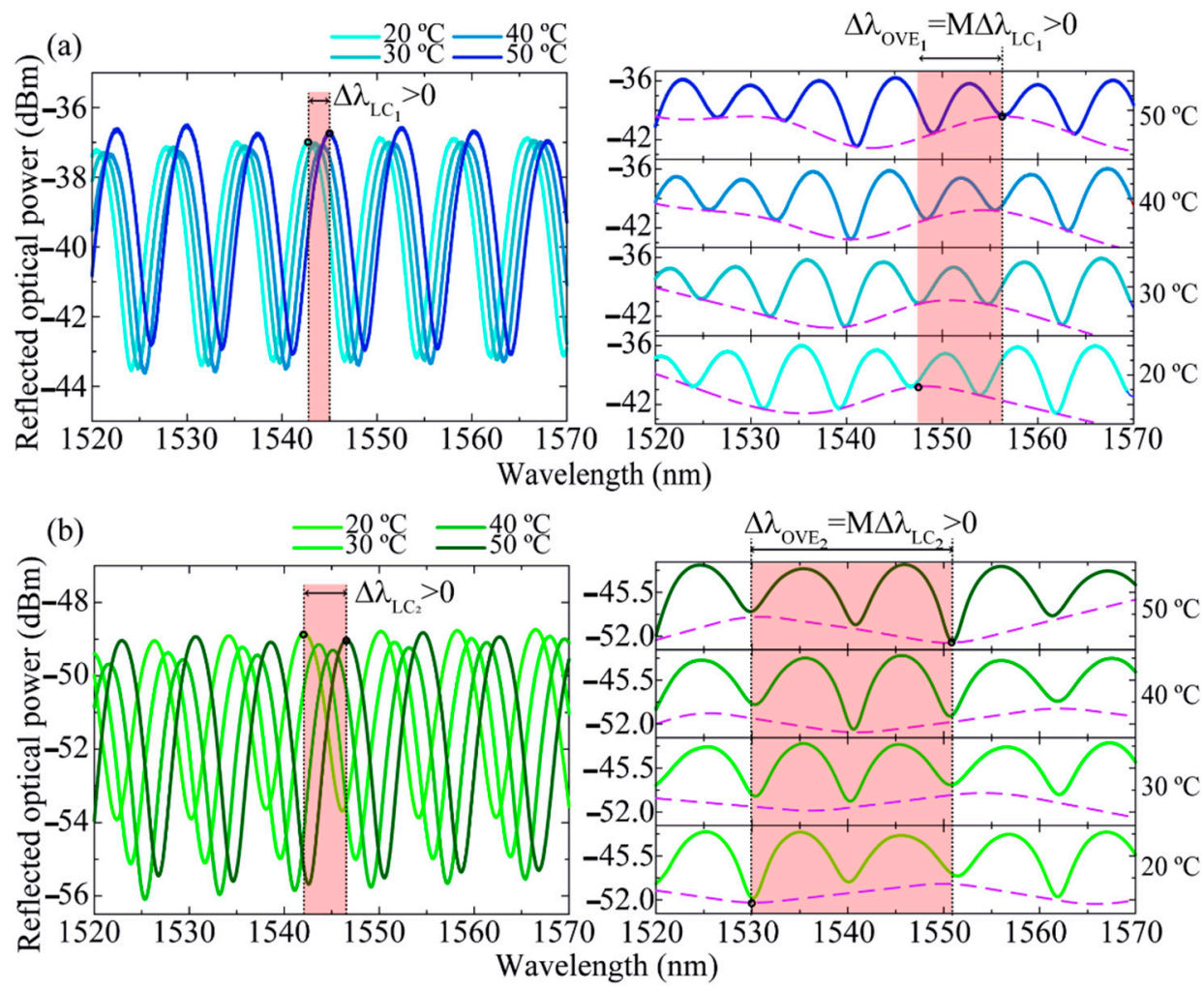

Figure 7. Spectra of (a) $\mathrm{LC}_{1} / \mathrm{OVE}_{1}$ and (b) $\mathrm{LC}_{2} / \mathrm{OVE}_{2}$ for four different temperature values. On the right, the purple dashed lines represent the lower envelopes of the OVE-based sensors.

The peaks' central wavelength shifts of $\mathrm{LC}_{1} / \mathrm{LC}_{2}$ and $\mathrm{OVE}_{1} / \mathrm{OVE}_{2}$ with temperature variations were monitored, resulting in the data presented in Figure 8.

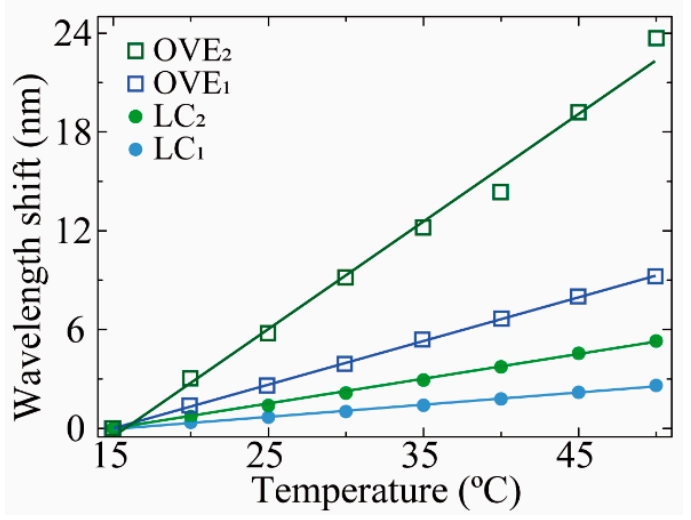

Figure 8. The wavelength shift of $\mathrm{LC}_{1}$ (closed blue circle), $\mathrm{LC}_{2}$ (closed green circle), $\mathrm{OVE}_{1}$ (opened blue square), and $\mathrm{OVE}_{2}$ (opened green square) with temperature. The colored solid lines represent the linear fits applied to each respective dataset.

By applying linear fitting to the data presented in Figure 8, the maximum thermal sensitivity $\left(\mathrm{S}_{\mathrm{T}}\right)$ of $0.66 \pm 0.03 \mathrm{~nm}^{\circ} \mathrm{C}^{-1}$ was attained with $\mathrm{OVE}_{2}$, representing a magnification factor value of $\mathrm{M}=4.3 \pm 0.3$ relative to the sensitivity value achieved with the $\mathrm{LC}_{2}$ $\left(0.153 \pm 0.002 \mathrm{~nm}^{\circ} \mathrm{C}^{-1}\right.$, Table 2). It should be noted that the sensitivities observed for $\mathrm{LC}_{1}$ and $L_{2}$ are due to their resin encapsulation: with the thermal variations, the resin will expand/contract, inducing a correspondent strain in the hollow cavity and correspondent wavelength shift of the FPI spectra. 
Table 2. Summary of the $\mathrm{LC}_{1}, \mathrm{LC}_{2}, \mathrm{OVE}_{1}$ and $\mathrm{OVE}_{2}$ sensitivities to temperature $\left(\mathrm{S}_{\mathrm{T}}\right)$ and normal load $\left(\mathrm{S}_{\text {Load }}\right)$ variations.

\begin{tabular}{ccccccc}
\hline Sensor & $\begin{array}{c}\mathbf{S}_{\mathbf{T}} \\
\left(\mathbf{n m}{ }^{\circ} \mathbf{C}^{-\mathbf{1}}\right)\end{array}$ & $\mathbf{R}^{\mathbf{2}}$ & $\mathbf{M}$-Factor & $\begin{array}{c}\mathbf{S}_{\text {Load }} \\
\left(\mathbf{n m ~ N} \mathbf{~ N}^{-1}\right)\end{array}$ & $\mathbf{R}^{\mathbf{2}}$ & $\begin{array}{c}\text { M- } \\
\text { Factor }\end{array}$ \\
\hline $\mathrm{LC}_{1}$ & $0.074 \pm 0.001$ & 0.998 & - & $0.053 \pm 0.001$ & 0.999 & - \\
$\mathrm{LC}_{2}$ & $0.153 \pm 0.002$ & 0.999 & - & $0.102 \pm 0.001$ & 0.999 & - \\
$\mathrm{OVE}_{1}$ & $0.265 \pm 0.002$ & 0.999 & $3.6 \pm 0.1$ & $0.182 \pm 0.004$ & 0.988 & $3.4 \pm 0.1$ \\
$\mathrm{OVE}_{2}$ & $0.66 \pm 0.03$ & 0.988 & $4.3 \pm 0.3$ & $0.433 \pm 0.005$ & 0.998 & $4.2 \pm 0.1$ \\
\hline
\end{tabular}

To assess the sensors' responses to vertical load, the developed sensors were mounted on a mechanical test machine (Shimadzu ${ }^{\circledR}$, AGS-5 kND). The spectral responses of both sensing elements $\left(\mathrm{LC}_{1}\right.$ and $\left.\mathrm{LC}_{2}\right)$ were monitored for a load range of $0-150 \mathrm{~N}$, approximately, resulting in the data plotted in Figure 9.

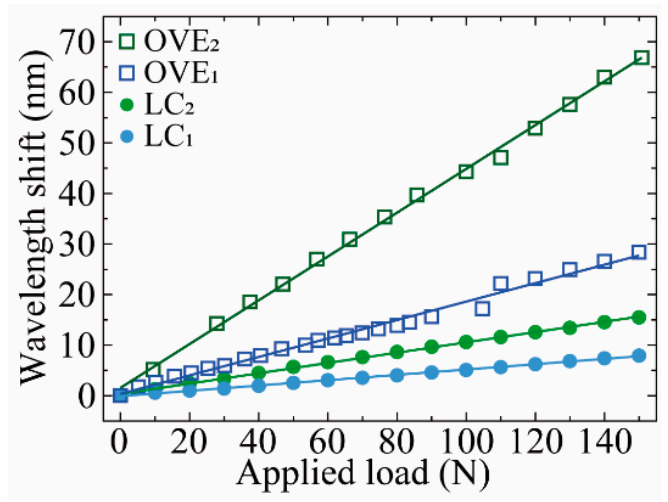

Figure 9. Wavelength shift of $\mathrm{LC}_{1}$ (closed blue circle), $\mathrm{LC}_{2}$ (closed green circle), $\mathrm{OVE}_{1}$ (opened blue square) and $\mathrm{OVE}_{2}$ (opened green square) with applied load force. The solid lines represent the linear fits applied to the respective data.

Analogous to the temperature characterization, the linear fits applied to the vertical load characterization data revealed that $\mathrm{OVE}_{2}$ attained the highest load sensitivity value $\left(S_{\text {Load }}=0.433 \pm 0.005 \mathrm{~nm} \mathrm{~N}^{-1}\right)$, which translates to a magnification factor of $\mathrm{M}=4.2 \pm 0.1$ (Table 2), and presented a high linear correlation factor $\left(R^{2}>0.998\right)$. The higher sensitivity values of $\mathrm{OVE}_{2}$ may be explained not only by the magnification provided by the optical Vernier effect but may also be due to the sensing FPI intrinsic physical characteristics, namely its dimensions and shape. As temperature and load variations are transduced as strain to the FPI cavities, it is known that the larger the FPI physical length is, or the lower FSR value (in this case, $\mathrm{FSR}_{\mathrm{LC} 1} \approx 7.67 \mathrm{~nm}$ and $\mathrm{FSR}_{\mathrm{LC} 2} \approx 8.13 \mathrm{~nm}$ ), the less sensitive to strain variations it will be, as suggested in [19].

From the results presented in Table 2, it can be verified that all load cells' configurations present linear behavior for both temperature and normal load variations. However, slight structural differences in the sensing elements (volume of load cells and physical dimensions of the sFPIs) may lead to major sensitivity discrepancies, even if the same resin material is used, as occurred in $\mathrm{LC}_{1}$ and $\mathrm{LC}_{2}$. Therefore, since similar magnification values were provided to $\mathrm{OVE}_{1}$ and $\mathrm{OVE}_{2}$ by the optical Vernier effect, the higher sensitivities achieved by $\mathrm{OVE}_{2}$ were expected. The maximum theoretical resolutions were calculated for this device, attaining the values of $0.008{ }^{\circ} \mathrm{C}$ and $0.012 \mathrm{~N}$ for temperature and load, respectively, determined by dividing the optical interrogator wavelength resolution by the attained sensitivities. The results presented in this work corroborate the use of the proposed sensor scheme to monitor temperature and normal load variations, with a sensitivity performance comparable with works already reported in the literature $[17,18,20]$, but for a wider range of applied normal load (0-150 N). 


\section{Conclusions}

In summary, a novel optical fiber sensor architecture for vertical load sensing was developed based on hollow FPI cavities embedded in epoxy resin (LiquidLens Advanced). The highest load sensitivity values were attained for the load cell with higher encapsulating dimensions $\left(\mathrm{LC}_{2}\right)$, corroborating the use of similar physical parameters to develop new load cells in the future. By coupling the $\mathrm{LC}_{1}$ and $\mathrm{LC}_{2}$ cavities with a similar non-embedded one in a parallel configuration, the optical Vernier effect was generated, attaining a maximum vertical load sensitivity of $0.433 \mathrm{~nm} \mathrm{~N}^{-1}$, which is $\sim 4.2$ times higher than the sensitivity value of the single $\mathrm{LC}_{2}$ FPI sensor $\left(0.102 \mathrm{~nm} \mathrm{~N}^{-1}\right)$. Despite presenting relatively hightemperature sensitivities, in the future, cross-sensitivity issues could be mitigated by using both load sensors simultaneously and the respective $2 \times 2$ sensitivity matrix or by using another temperature sensor as a reference. As the rFPI used to generate the OVE is insensitive to temperature, the sensing architecture complexity was further reduced since mathematical compensations and isolation schemes are not required. Therefore, the small footprint and high sensing resolutions of the proposed sensors make them a suitable and valid solution for many sensing challenges, especially for those where very sensitive and compact load sensors are required.

Author Contributions: Conceptualization, T.P., M.F.D. and P.A.; methodology, T.P., R.F., M.F.D. and P.A.; validation, T.P., R.F. and M.F.D.; formal analysis, T.P. and R.F.; investigation, T.P. and R.F.; data curation, T.P. and R.F.; writing — original draft preparation, T.P.; writing — review and editing, T.P., R.F., M.F.D. and P.A. All authors have read and agreed to the published version of the manuscript.

Funding: This research was funded by national funds through the Fundação para a Ciência e a Tecnologia (FCT)/MEC and FCT/MCTES) and, when applicable, co-funded by EU funds and FEDER-PT2020, within the scope of the projects I3N UIDB/50025/2020, UIDP/50025/2020, and UID/EEA/50008/2019.

Institutional Review Board Statement: Not applicable.

Informed Consent Statement: Not applicable.

Data Availability Statement: Not applicable.

Conflicts of Interest: The authors declare no conflict of interest.

\section{References}

1. Peters, K. Polymer optical fiber sensors-A review. Smart Mater. Struct. 2011, 20, 013002. [CrossRef]

2. Yin, S.; Ruffin, P.B.; Yu, F.T.S. Fiber Optic Sensors; CRC Press-Taylor \& Francis Group: Boca Raton, FL, USA, 2008; ISBN 978-1-4200-5365-4.

3. Gomes, A.D.; Becker, M.; Dellith, J.; Zibaii, M.I.; Latifi, H.; Rothhardt, M.; Bartelt, H.; Frazão, O. Multimode Fabry-Perot Interferometer Probe Based on Vernier Effect for Enhanced Temperature Sensing. Sensors 2019, 19, 453. [CrossRef] [PubMed]

4. Paixão, T.; Araújo, F.; Antunes, P. Highly sensitive fiber optic temperature and strain sensor based on an intrinsic Fabry-Perot interferometer fabricated by a femtosecond laser. Opt. Lett. 2019, 44, 4833. [CrossRef] [PubMed]

5. Paixão, T.; Ferreira, R.; Araújo, F.; Antunes, P. Hybrid intrinsic optical fiber sensor fabricated by femtosecond laser with enhanced sensitivity by Vernier effect. Opt. Laser Technol. 2021, 133, 106520. [CrossRef]

6. Zhang, P.; Tang, M.; Gao, F.; Zhu, B.; Fu, S.; Ouyang, J.; Shum, P.P.; Liu, D. Cascaded fiber-optic Fabry-Perot interferometers with Vernier effect for highly sensitive measurement of axial strain and magnetic field. Opt. Express 2014, 22, 19581. [CrossRef] [PubMed]

7. Xu, Z.; Sun, Q.; Li, B.; Luo, Y.; Lu, W.; Liu, D.; Shum, P.P.; Zhang, L. Highly sensitive refractive index sensor based on cascaded microfiber knots with Vernier effect. Opt. Express 2015, 23, 6662. [CrossRef] [PubMed]

8. Zhang, Y.; Li, Y.; Liu, Y.; Gong, Z.; Liao, Y.Y.; Wang, X.S.; Chen, Q.M.; Yang, D.H.; Qu, S.L. Sensitivity amplification of bubble-based all-silica fiber liquid-pressure sensor by using femtosecond laser exposure. Opt. Commun. 2020, 462, 125291. [CrossRef]

9. Gomes, A.D.; Kobelke, J.; Bierlich, J.; Dellith, J.; Rothhardt, M.; Bartelt, H.; Frazão, O. Giant refractometric sensitivity by combining extreme optical Vernier effect and modal interference. Sci. Rep. 2020, 10, 19313. [CrossRef] [PubMed]

10. Domingues, M.D.F.; Rosa, V.; Nepomuceno, A.C.; Tavares, C.; Alberto, N.; Andre, P.; Radwan, A.; da Costa Antunes, P.F. Wearable Devices for Remote Physical Rehabilitation Using a Fabry-Perot Optical Fiber Sensor: Ankle Joint Kinematic. IEEE Access 2020, 8 , 109866-109875. [CrossRef]

11. Domingues, M.F.; Antunes, P.; Alberto, N.; Frias, R.; Ferreira, R.A.S.; André, P. Cost effective refractive index sensor based on optical fiber micro cavities produced by the catastrophic fuse effect. Measurement 2016, 77, 265-268. [CrossRef] 
12. Antunes, P.F.C.; Domingues, M.F.F.; Alberto, N.J.; André, P.S. Optical Fiber Microcavity Strain Sensors Produced by the Catastrophic Fuse Effect. IEEE Photonics Technol. Lett. 2014, 26, 78-81. [CrossRef]

13. Gomes, A.D.; Bartelt, H.; Frazão, O. Optical Vernier Effect: Recent Advances and Developments. Laser Photon. Rev. 2021, 15, 2000588. [CrossRef]

14. Liu, Y.; Li, X.; Zhang, Y.N.; Zhao, Y. Fiber-optic sensors based on Vernier effect. Meas. J. Int. Meas. Confed. 2021, 167, 108451. [CrossRef]

15. Liu, S.; Wang, Y.; Liao, C.; Wang, G.; Li, Z.; Wang, Q.; Zhou, J.; Yang, K.; Zhong, X.; Zhao, J.; et al. High-sensitivity strain sensor based on in-fiber improved Fabry-Perot interferometer. Opt. Lett. 2014, 39, 2121-2124. [CrossRef] [PubMed]

16. Li, J.; Zhang, M.; Wan, M.; Lin, C.; Huang, S.; Liu, C.; He, Q.; Qiu, X.; Fang, X. Ultrasensitive refractive index sensor based on enhanced Vernier effect through cascaded fiber core-offset pairs. Opt. Express 2020, 28, 4145. [CrossRef] [PubMed]

17. Wu, Y.; Liu, B.; Wu, J.; Zhao, L.; Sun, T.; Mao, Y.; Nan, T.; Wang, J. A Transverse Load Sensor with Ultra-Sensitivity Employing Vernier-Effect Improved Parallel-Structured Fiber-Optic Fabry-Perot Interferometer. IEEE Access 2019, 7, 120297-120303. [CrossRef]

18. Wang, J.; Liu, B.; Wu, Y.; Mao, Y.; Zhao, L.; Sun, T.; Nan, T.; Han, Y. Temperature insensitive fiber Fabry-Perot/Mach-Zehnder hybrid interferometer based on photonic crystal fiber for transverse load and refractive index measurement. Opt. Fiber Technol. 2020, 56, 102163. [CrossRef]

19. Ferreira, M.S.; Bierlich, J.; Kobelke, J.; Schuster, K.; Santos, J.L.; Frazão, O. Towards the control of highly sensitive Fabry-Pérot strain sensor based on hollow-core ring photonic crystal fiber. Opt. Express 2012, 20, 21946. [CrossRef] [PubMed]

20. Jauregui-Vazquez, D.; Lopez-Dieguez, Y.; Sierra-Hernandez, J.M.; Perez-Maciel, M.; Avila-Garcia, M.S.; Vargas-Rodriguez, E.; Rojas-Laguna, R.; Estudillo-Ayala, J.M. Modified All-Fiber Fabry-Perot Interferometer and Its Refractive Index, Load, and Temperature Analyses. IEEE Photonics J. 2015, 7, 1-9. [CrossRef] 